\title{
The influence of simultaneous feeding of different species of aphids on photosynthesis intensity of blackcurrant and high bush blueberry
}

\author{
Wpływ równoczesnego żerowania różnych gatunków mszyc \\ na intensywność fotosyntezy porzeczki czarnej i borówki wysokiej
}

\author{
Anna Tomczyk, Joanna Wróblewska
}

\section{Summary}

The studies were conducted in the Department of Applied Entomology at Warsaw University of Life Sciences, in the field and laboratory conditions. The aim of this study was to determine the influence of aphids on the process of photosynthesis of blackcurrant cultivar Titania (attacked mainly by Aphis schneideri Börn.) and high bush blueberry cultivar Patriot (attacked by Myzus persicae Sulz and Aphis fabae Scop.). The chlorophyll content in the leaves was also estimated. The significant decrease of photosynthesis intensity was found in the leaves of blackcurrant and high bush blueberry as a result of aphid feeding, as compared to healthy ones, 32 and $27 \%$ respectively. The tendency for the increase of photosynthesis intensity in black currant leaves, not injured by aphids but originated from attacked shoots, in comparison with the leaves from healthy shoots, was observed. Chlorophyll content in the leaves of both experimental plants significantly decreased as a result of aphid feeding, especially in the case of black currant (decrease in chlorophyll $a+b$ about $32 \%)$.

Key words: black currant, high bush blueberry, aphids feeding, photosynthesis, chlorophyll content

\section{Streszczenie}

Badania prowadzono w Katedrze Entomologii Stosowanej Szkoły Głównej Gospodarstwa Wiejskiego w Warszawie, w warunkach polowych i laboratoryjnych. Celem ich było określenie szkodliwego wpływu mszyc na proces fotosyntezy porzeczki czarnej odmiany Titania (zaatakowana głównie przez Aphis schneideri Börn.) i borówki wysokiej odmiany Patriot (zaatakowanej przez Myzus persicae Sulz and Aphis fabae Scop.). Wykonano także analizę zawartości chlorofilu w liściach. Wykazano istotne ograniczenie intensywności fotosyntezy w uszkodzonych przez mszyce liściach porzeczki czarnej i borówki wysokiej w porównaniu z liśćmi zdrowymi, odpowiednio o 32 i 27\%. Zaobserwowano tendencje do wzrostu intensywności fotosyntezy w liściach porzeczki nieuszkodzonych przez mszyce, lecz znajdujących się na uszkodzonym pędzie, w porównaniu do liści z pędów nieuszkodzonych. Zawartość chlorofilu w liściach obu badanych roślin istotnie zmniejszyła się w wyniku żerowania mszyc, szczególnie w przypadku porzeczki czarnej (spadek chlorofilu a + b o $32 \%)$.

Słowa kluczowe: porzeczka czarna, borówka wysoka, żerowanie mszyc, fotosynteza, zawartość chlorofilu

Szkoła Główna Gospodarstwa Wiejskiego w Warszawie

Katedra Entomologii Stosowanej

Nowoursynowska 166, 02-787 Warszawa

anna_tomczyk@sggw.pl 


\section{Wstęp / Introduction}

Mszyce należą do bardzo groźnych szkodników krzewów owocowych, zarówno ze względu na bezpośrednie uszkodzenia pędów, jak również z powodu możliwości przenoszenia i rozprzestrzeniania wirusów.

Krzewy porzeczki czarnej są zasiedlane przez takie gatunki, jak: Cryptomyzus ribis L., C. galeopsidis Kalt., Aphis grossulariae Kalt., A. schneideri Börn., Hyperomyzus lactucae L., H. pallidus HTL, Nasonovia ribisnigri Mosley, czy Schizoneura ulmi L. (Cichocka 1980). Żerowanie mszyc może prowadzić do lokalnej martwicy komórek, różnego rodzaju przebarwień, deformacji liści lub całych pędów oraz zmian histologicznych prowadzących do powstawania różnego typu wyrośli (Avery 1966; Miles 1999; Mitchell i wsp. 2011). Zarówno zmiany morfologiczne, jak i metaboliczne uszkodzonych roślin, mogą mieć istotny wpływ na ich proces fotosyntezy (Tomczyk i Goszczyński 1996). Do najważniejszych przyczyn obserwowanego często ograniczenia procesu fotosyntezy u roślin uszkodzonych przez mszyce należą: zmniejszenie powierzchni asymilacyjnej (na skutek deformacji liści) i utrata barwników fotosyntetycznych, chlorofilu a i b. Żerowanie mszyc na różnych gatunkach roślin żywicielskich wiąże się bardzo często z deformacją liści lub całych pędów. Najsilniej zdeformowane są zwykle liście na wierzchołkach pędów, których rola $\mathrm{w}$ procesie fotosyntezy jest z reguły największa. Określenie utraconej powierzchni liści na skutek ich deformacji jest ważnym elementem oceny zmniejszenia możliwości fotosyntetycznej uszkodzonej rośliny. Ograniczenie intensywności fotosyntezy porzeczki czarnej wpływa negatywnie na plonowanie roślin.

Krzewy borówki wysokiej zasiedlane są przez kilka gatunków mszyc: A. fabae Scop., Myzus persicae Sulz., Illinoia pepperi MacGillivray (Łabanowska 2007). Na plantacjach borówki wysokiej w Polsce mszyce zwykle rozpoczynają żerowanie późną wiosną (gatunki dwudomne: A. fabae, M. persicae) i nie tworzą dużych kolonii, przez co powodowane przez nie uszkodzenia mogą być mniejsze $\mathrm{W}$ porównaniu $\mathrm{z}$ zaatakowaną przez mszyce porzeczką czarną. Znane są jednak doniesienia o dużej szkodliwości mszyc żerujących na borówce w innych krajach, głównie w Stanach Zjednoczonych (Ranger i wsp. 2006).

Celem badań było określenie wpływu żerowania mszyc na proces asymilacji dwutlenku węgla.

\section{Materiały i metody / Materials and methods}

Badania prowadzono na liściach roślin porzeczki czarnej odmiany Titania zaatakowanej przez: A. schneideri i C. ribis oraz borówki wysokiej odmiany Patriot zaatakowanej przez: A. fabae i $M$. persicae. Badano: ubytek powierzchni liści, wywołany ich deformacją przez mszyce, intensywność fotosyntezy oraz zawartość chlorofilu w liściach.

Do badań prowadzonych na porzeczce czarnej wykorzystano liście uszkodzone przez duże kolonie mszyc (kilkadziesiąt osobników), liście z nieuszkodzonych pędów (kontrolne) oraz liście nieuszkodzone, położone bezpośrednio pod uszkodzonymi, na zasiedlonych przez mszyce pędach. W badaniach prowadzonych na borówce wysokiej wykorzystywano liście nieuszkodzone i uszkodzone przez niewielkie kolonie mszyc (kilkanaście osobników). Przed pomiarami usuwano mszyce $\mathrm{z}$ liści. Intensywność fotosyntezy netto mierzono na odciętych liściach badanych roślin, przy pomocy analizatora $\mathrm{CO}_{2}$ LI-COR 6400XT. Ogonki liści zabezpieczono wilgotną watą i umieszczono w plastikowych torebkach na okres adaptacji do warunków świetlnych (10 minut). Pomiar przeprowadzono w kamerze fotosyntetycznej ze światłem RedBlue LED o natężeniu $800 \mu \mathrm{mol} / \mathrm{m}^{2}$, przy standardowym stężeniu $\mathrm{CO}_{2}$ wynoszącym $400 \mathrm{ppm}$. Intensywność fotosyntezy wyrażono $\mathrm{w} \mu \mathrm{l}$ $\mathrm{CO}_{2} / \mathrm{m}^{2} / \mathrm{s}$. Pomiary wykonano w 10 powtórzeniach dla każdego wariantu doświadczalnego.

Chlorofil oznaczano w uprzednio zamrożonych liściach $\left(-70^{\circ} \mathrm{C}\right)$. Chlorofil ekstrahowano poprzez homogenizację pobranych prób (100 mg) w $80 \%$ acetonie. Homogenat odwirowywano przy $10000 \mathrm{~g}$ przez 15 minut, w temperaturze $4^{\circ} \mathrm{C}$. Ekstrakty uzupełniono do stałej objętości $80 \%$ acetonem i oznaczono zawartość chlorofilu a i b, odpowiednio przy długości fali 645 i $663 \mathrm{~nm}$. Zawartość chlorofilu określano według metody opisanej przez Lichtenthaler i Wellburn (1983).

Powierzchnię liści obu gatunków roślin doświadczalnych oznaczano metodą wagową. Po porównaniu powierzchni liścia uszkodzonego i kontrolnego oceniono procentowy ubytek powierzchni asymilacyjnej w wyniku żerowania mszyc.

\section{Wyniki i dyskusja / Results and discussion}

Wyniki pomiarów powierzchni liści porzeczki czarnej i borówki wysokiej uszkodzonych i nieuszkodzonych przez mszyce przedstawiono na rysunkach 1. i 2.

W wyniku żerowania mszyc na liściach porzeczki czarnej, zmniejszona została ich średnia powierzchnia aż

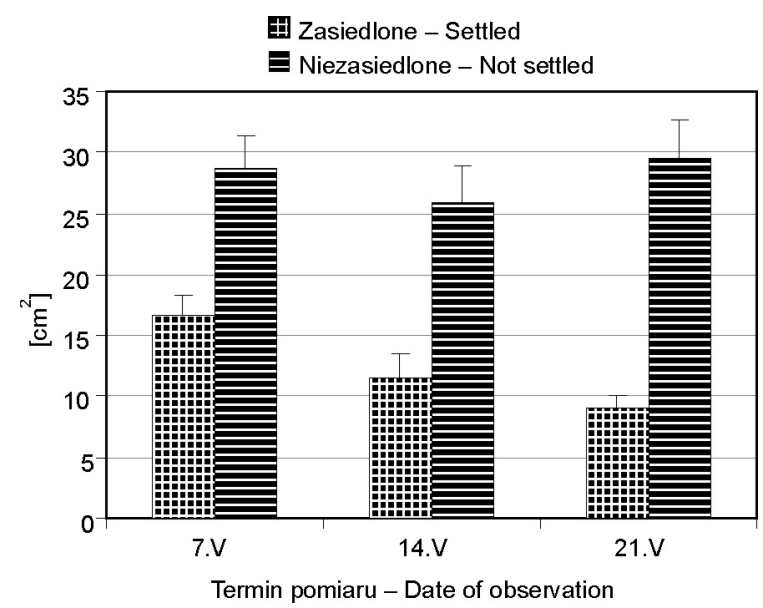

Rys. 1. Średnia powierzchnia liści porzeczki czarnej zasiedlonych i niezasiedlonych przez mszyce. Zaprezentowano wartości SE

Fig. 1. The average area of blackcurrant leaves settled and not settled by aphids. SE values are presented 


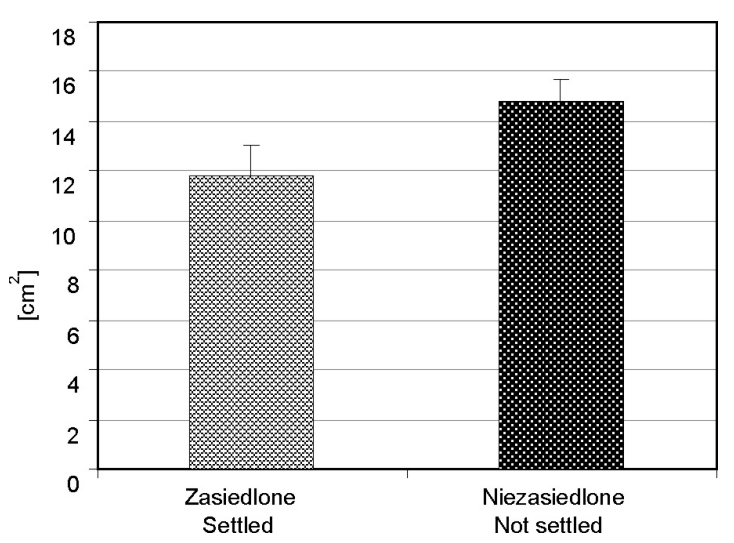

Rys. 2. Średnia powierzchnia liści borówki wysokiej zasiedlonych i niezasiedlonych przez mszyce. Zaprezentowano wartości SE

Fig. 2. The average area of highbush blueberry leaves settled and not settleded by aphids. SE values are presented

o $70 \%$. W przypadku borówki wysokiej zaobserwowano zmniejszenie powierzchni uszkodzonych liści, w porównaniu z kontrolnymi, o 20\%. Mniejsze ubytki powierzchni fotosyntetycznej borówki zaatakowanej przez mszyce, w porównaniu $\mathrm{z}$ porzeczką, związane były z żerowaniem dużo mniejszych kolonii mszyc na tej roślinie.

Intensywność fotosyntezy w liściach porzeczki czarnej zaatakowanych i niezaatakowanych przez mszyce przedstawiono na rysunku 3. Po miesiącu żerowania populacji mszyc, intensywność fotosyntezy w uszkodzonych liściach porzeczki czarnej spadła o $32 \%$ w porównaniu do liści kontrolnych. Różnica ta była istotna statystycznie (F = $35,20 ;$ p-value $=0,00)$. Pomiędzy intensywnością fotosyntezy w liściach uszkodzonych i nieuszkodzonych położonych bezpośrednio pod uszkodzonymi, nie zaobserwowano istotnych statystycznie różnic $(\mathrm{F}=0,91$; $\mathrm{p}$-value $=$ $0,35)$, chociaż uwidoczniła się pewna tendencja do stymulacji procesu fotosyntezy w liściach nieuszkodzonych pobranych z zasiedlonego przez mszyce pędu.

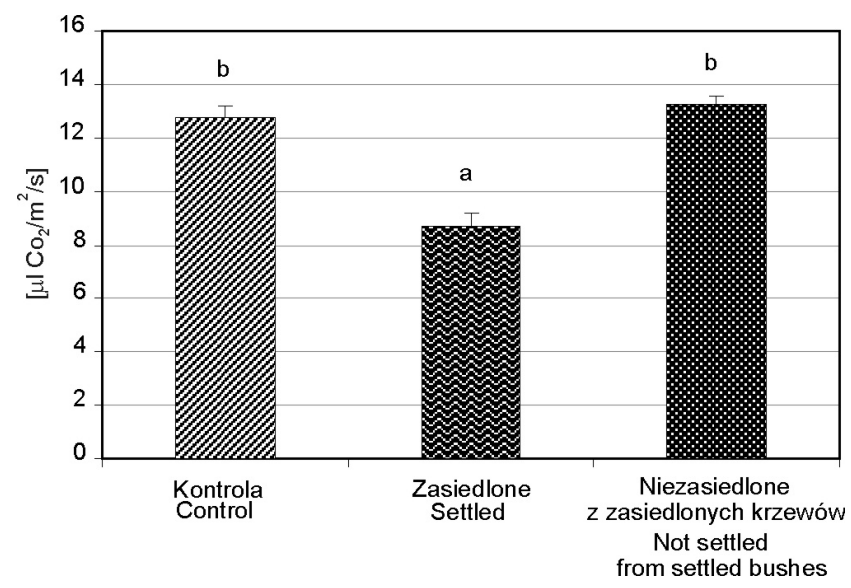

Rys. 3. Intensywność fotosyntezy liści porzeczki zasiedlonych i niezasiedlonych przez mszyce. Zaprezentowano wartości SE. Różne litery nad słupkami wskazują na istotność różnic

Fig. 3. Photosynthesis intensity of currant leaves settled and not settled by aphids. SE values are presented. Different letters above the bars indicate significance of differences

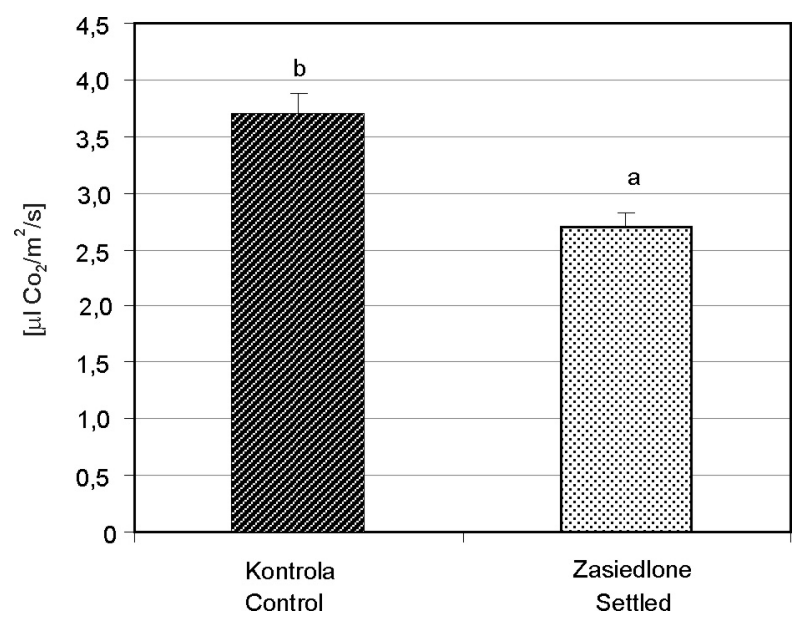

Rys. 4. Intensywność fotosyntezy liści borówki zasiedlonych i nie-zasiedlonych przez mszyce. Zaprezentowano wartości SE. Różne litery nad słupkami wskazują na istotność różnic

Fig. 4. Photosynthesis intensity of blueberry leaves settled and not settled by aphids. SE values are presented. Different letters above the bars indicate significance of differences

Intensywność fotosyntezy liści borówki wysokiej w liściach zaatakowanych i niezaatakowanych przez mszyce przedstawiono na rysunku 4 . W przypadku borówki wysokiej zaobserwowano spadek intensywności fotosyntezy w liściach uszkodzonych, w porównaniu $\mathrm{z}$ nieuszkodzonymi, o $27 \%$. Różnica ta była istotna statystycznie $(\mathrm{F}=22,50 ; \mathrm{p}$-value $=0,00)$. Ograniczenie intensywności fotosyntezy $\mathrm{w}$ uszkodzonych przez mszyce liściach obu roślin wynikało przede wszystkim ze zmniejszenia w nich zawartości chlorofilu. Spadek zawartości chlorofilu był silniejszy w uszkodzonych liściach porzeczki czarnej, W porównaniu z uszkodzonymi liśćmi borówki wysokiej (rys. 5, 6). W bezpośrednio uszkodzonych przez mszyce liściach porzeczki wystąpił spadek chlorofilu $\mathrm{a}+\mathrm{b}$ o około $32 \%$, różnica ta była istotna statystycznie $(\mathrm{F}=18,32$; p-value $=0,00)$. Żerowanie mszyc szczególnie negatywnie wpłynęło na zawartość chlorofilu b (zmniejszenie o 55\%

Kontrola-Control $\square$ Zasiedlone-Settled $\quad$ ENiezasiedlone-Not settled

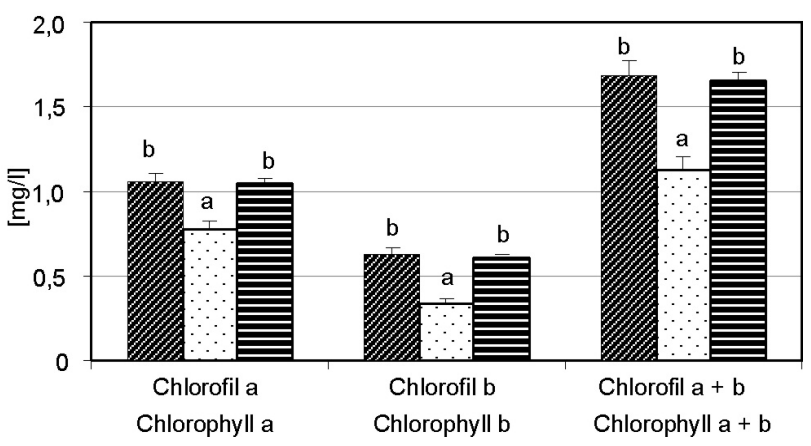

Rys. 5. Zawartość chlorofilu w liściach porzeczki zasiedlonych i niezasiedlonych przez mszyce. Zaprezentowano wartości SE. Różne litery nad słupkami wskazują na istotność różnic

Fig. 5. Chlorophyll content in currant leaves settled and not settled by aphids. SE values are presented. Different letters above the bars indicate significance of differences 


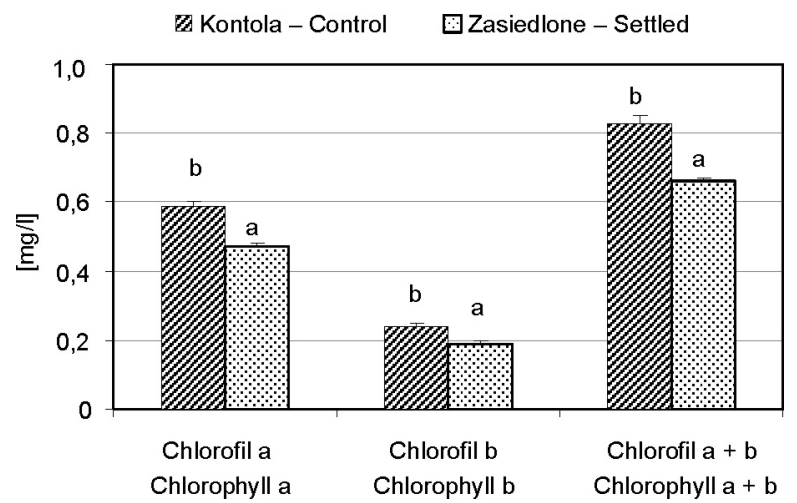

Rys. 6. Zawartość chlorofilu w liściach borówki zasiedlonych i niezasiedlonych przez mszyce. Zaprezentowano wartości SE. Różne litery nad słupkami wskazują na istotność różnic

Fig. 6. Chlorophyll content in blueberry leaves settled and not settled by aphids. SE values are presented. Different letters above the bars indicate significance of differences

w porównaniu z liśćmi kontrolnymi). W liściach borówki, na których żerowały mszyce, zawartość chlorofilu zarówno a i b spadła o około 20\%. Różnica ta była istotna statystycznie $(\mathrm{F}=39,04 ; \mathrm{p}$-value $=0,00)$. Otrzymane wyniki analizy zawartości chlorofilu są podobne do wyników otrzymanych przez innych autorów w badaniach nad żerowaniem mszyc na różnych roślinach żywicielskich. Khattab (2007) wykazał spadek zawartości chlorofilu po żerowaniu mszyc na kapuście o ponad $60 \%$. Podobne wyniki otrzymali Ni i wsp. (2002), którzy wykazali, że Diuraphis noxia Kurd. powoduje znaczne obniżenie zawartości chlorofilu w uszkodzonych organach w porównaniu do kontrolnych.

Żerowanie mszyc negatywnie wpłynęło na możliwości fotosyntetyczne badanych roślin przede wszystkim z dwóch powodów: utraty powierzchni asymilacyjnej liści, spowodowane ich silną deformacją (zwłaszcza w przypad$\mathrm{ku}$ żerowania mszyc na porzeczce czarnej) oraz silnego zmniejszenia zawartości chlorofilu w liściach zaatakowanych przez mszyce. Należy uwzględnić także możliwość wystąpienia zaburzeń metabolicznych w uszkodzonych pędach, wywołanych wprowadzaniem śliny szkodnika w czasie żerowania (Miles 1999). Uzyskane wyniki są zgodne $\mathrm{z}$ badaniami prowadzonymi przez Tomczyk i Goszczyńskiego (1996), którzy wykazali silny spadek intensywności fotosyntezy po dłuższym okresie żerowania mszycy $H$. lactucae. Obniżenie intensywności tego procesu na skutek żerowania mszyc obserwowali również w swoich badaniach Avery (1966) oraz Maneva i wsp. (2010).

\section{Wnioski / Conclusions}

1. Żerowanie mszyc ma negatywny wpływ na procesy metaboliczne zasiedlonych krzewów owocowych.

2. Mszyce negatywnie wpływają na intensywność procesu fotosyntezy porzeczki czarnej i borówki wysokiej, głównie $\mathrm{z}$ powodu utraty chlorofilu w uszkodzonych liściach.

3. Mszyce ograniczają powierzchnię blaszki liściowej porzeczki czarnej i borówki wysokiej, co znacznie zmniejsza możliwości fotosyntetyczne uszkodzonych roślin.

\section{Literatura / References}

Avery D. 1966. Growth of black currant infested with currant - lettuce aphid. J. Hortic. Sci. Biotechnol. 41: 189-196.

Cichocka E. 1980. Mszyce roślin sadowniczych Polski. PWN, Warszawa, 119 ss.

Khattab H. 2007. The defense mechanizm of cabbage plant against phloem-sucking aphid (Brevicoryne brassicae L.). Aust. J. Basic Appl. Sci. 1 (1): 56-62.

Lichtenthaler H., Wellburn A. 1983. Determinations of total carotenoids and chlorophylls $a$ and $b$ of leaf extracts in different solvents. Biochem. Soc. Trans. 11: 591-592.

Łabanowska B. 2007. Szkodniki na borówce wysokiej. http://www.ho.haslo.pl/article.php?id=3047. Dostęp: 07.03.2013.

Maneva V., Lecheva I., Vassilev A., Semerdjieva I. 2010. Changes in the photosynthetic performance of infested leaves of two barley cultivars by aphids. http://sa.agr.hr/pdf/2010/sa2010_p0539.pdf. Accessed: 07.03.2013.

Miles P. 1999. Aphid saliva. Biological Reviews of the Cambridge Philosophical Society 74 (1): 41-85.

Mitchell C., Brennan R., Cross J. 2011. Arthropod pests of currant and gooseberry crops in the U.K. Agric. Forest Entomol. 4: 5-22.

Ni X., Quisenberry S., Heng-Moss T., Markwell J., Higley L., Baxendale F., Sarath G., Klucas R. 2002. Dynamic change in photosynthetic pigments and chlorophyll degradation elicited by cereal aphid feeding. Entomol. Exper. Appl. 105: 43-53.

Ranger C., Johnson-Cicalese J., Polavarapu S., Vorsa N. 2006. Evaluation of Vaccinium spp. for Illinoia pepperi (Hemiptera: Aphididae) performance and phenolic content. J. Econ. Entomol. 99 (4): 1474-1482.

Tomczyk A., Goszczyński W. 1996. Effect of the currant-sowthistle aphid, Hyperomyzus lectucae (L.) on blackcurrant metabolism. Aphids and Other Homopterous Insects 5: 189-195. 